\title{
CHEMOSPHERE
}

\section{Distribution and fate of organochlorine pesticide residues in sediments from the selected rivers in Taiwan}

\author{
Ruey-An Doong ${ }^{\mathrm{a}, *}$, Yuh-Chang Sun ${ }^{\mathrm{b}}$, Pei-Ling Liao ${ }^{\mathrm{a}}$, Ching-Kai Peng ${ }^{\mathrm{a}}$, \\ Shian-Chee $\mathrm{Wu}^{\mathrm{c}}$ \\ a Department of Nuclear Science, National Tsing Hua University, 101, Sec. 2, Kuang Fu Road, Hsinchu 30013, Taiwan, ROC \\ ${ }^{\mathrm{b}}$ Nuclear Science and Technology Development Center, National Tsing Hua University, Hsinchu 30013, Taiwan, ROC \\ ${ }^{\mathrm{c}}$ Graduate Institute of Environmental Engineering, National Taiwan University, Taipei 106, Taiwan, ROC
}

Received 24 April 2001; received in revised form 30 January 2002; accepted 30 January 2002

\begin{abstract}
The contamination of organochlorine pesticides (OCPs) in sediments from selected rivers in Taiwan was investigated to evaluate the pollution potentials and hazard in river sediments. Da-han River and Erh-jen River were selected as the target rivers due to their serious pollution. A total of 40 surface sediment samples were collected at five sampling stations along the rivers. Results showed that the concentrations of various pesticides in sediments were in the range of $0.57-14.1 \mathrm{ng} / \mathrm{g}$ for $\sum \mathrm{HCH}, 0.05-0.15 \mathrm{ng} / \mathrm{g}$ for aldrin, $0.12-5.8 \mathrm{ng} / \mathrm{g}$ for dieldrin, $0.22-0.64$ for endrin, $0.24-6.37 \mathrm{ng} / \mathrm{g}$ for endosulfan and $0.21-8.81 \mathrm{ng} / \mathrm{g}$ for $\sum \mathrm{DDT}$ ( $p, p^{\prime}$-DDD, $p, p^{\prime}$-DDE, $p, p^{\prime}$-DDT). Among the OCPs, $\sum \mathrm{HCH}$, endosulfan and $\sum$ DDT were the most dominant compounds in the river sediments. Endosulfan sulfate was the most frequent detected compound in the sediments from the selected rivers. Also, $\sum$ DDT, dieldrin and $\beta-\mathrm{HCH}$ were in abundance. Different contamination patterns between the selected river sediments were also observed. Da-han River was mainly contaminated with endosulfan sulfate and $\sum D D T$. Whereas the main pesticides in Erh-jen River were $\beta-\mathrm{HCH}$ and $\sum$ DDT. Among the cyclodiene compounds, dieldrin was in abundance in most of the sediments. Moreover, the frequencies of detection of the metabolites were higher than those of parent compounds, depicting that the sediments have contaminated for a long time. The results obtained in this study showed that there still exist a variety of OCP residues in the river sediments in Taiwan. (C) 2002 Elsevier Science Ltd. All rights reserved.
\end{abstract}

Keywords: Organochlorine pesticides; Surface sediment; HCH; DDT; Distribution

\section{Introduction}

Organochlorine pesticides (OCPs) are known for their environmental persistence and global concerns. Residues of OCPs continue to detect in many areas. Owing to their high capacities for bioaccumulation and toxicities in organisms, these compounds pose threats to ecosystems and human health. Since these compounds have an

\footnotetext{
${ }^{*}$ Corresponding author. Tel.: +886-3-5726785; fax: +886-35718649.

E-mail address: radoong@mx.nthu.edu.tw (R.-A. Doong).
}

affinity for particulate matters, one of their major sinks is thought to be the river and marine sediments. Therefore, the investigation of distribution of OCPs in sediments can provide a valuable record of contamination in the aquatic environments.

The input pathways of OCPs into the river environments include discharge of domestic sewage and industrial wastewater, runoff from nonpoint sources, and direct dumping of wastes into the river. Although sediments do not constitute a direct measure of the degree of aquatic pollution, they offer an irreplaceable aid in reconstructing the historical inputs of OCPs based on profile descriptions of contamination in core samples 
(Hendy and Peake, 1996). The distribution of various contaminants in sediments depends largely on the physicochemical properties of the ecosystem, the partition coefficients of individual contaminants, the organic contents, and microflora activities (Pavoni et al., 1987; Brook and Moore, 1988; McKenzie-Smith et al., 1994; Glynn et al., 1995). Although the residue levels of the chlorinated compounds in the environments have considerably declined in the past 20 years, recent work has depicted that chlorinated pesticides could be detected in the range of 0.03-25.17 ng/g dry weight (d.w.) in marine and river sediments (Gold-Bouchot et al., 1995; Sarkar et al., 1997). Moreover, some OCPs, such as DDT, HCH and endosulfan are still used in some countries around the tropical and subtropical belts for agricultural and medicinal purposes. These compounds can be deposited into the sediments through long-range atmospheric transport (LRT), resulting in a high exposure to OCPs in the areas near the pollution sources.

Taiwan has a strong agricultural sector, which has made wide use of pesticides. The OCPs were employed extensively in the early 1950s for the control of soildwelling insects and have been officially banned since 1974. It is estimated that $2.5 \times 10^{7} \mathrm{~kg}$ of OCPs was released into the environments annually from the $1950 \mathrm{~s}$ to 1970 s and constituted a long-term source of contamination to aquatic ecosystem via soil erosion and agricultural runoff. A variety of OCP residues in foods from Hsinchu, Taiwan were also detected in the range of $0.26-10.22 \mathrm{ng} / \mathrm{g}$ wet weight (Doong and Lee, 1999). However, there is little information of the contamination of sediments in Taiwan rivers.

The purpose of this study was to determine the contamination level of OCPs in sediments from selected rivers to evaluate the pollution potentials and hazard of river sediments in Taiwan. Two different rivers, Da-han River and Erh-jen River were selected as the target rivers for studies in northern and southern Taiwan, respectively.

\section{Methods and materials}

\subsection{Study area and sampling}

The Da-han River, one of the important rivers in northern Taiwan, has a catchment basin of $1163 \mathrm{~km}^{2}$ and a total length of $135 \mathrm{~km}$. The Da-han River is a traditional agricultural production site which has small scale farms producing grains. Also, this river is a main source for water supply in northern Taiwan and receives massive discharge of domestic sewage from the urbanized areas in its catchment basin. The Erh-jen River, a representative polluted river in southern Taiwan, has a catchment area of $350 \mathrm{~km}^{2}$ and a total length of $65 \mathrm{~km}$.
The river water is highly polluted with heavy metals and dioxin from the industrial discharge.

A total of 40 sediment samples were collected from these two rivers from October 1997 to April 1998. Five sampling stations along each river were selected and four samples from each station were collected. The locations of these sampling stations in the selected rivers are shown in Fig. 1. The distances of sampling sites from the outlets of the selected rivers were 19.3, 22.9, 23.6, 27.2 and $41.2 \mathrm{~km}$ for Da-han River and 1.2, 6.3, 17.9, 24.6, and $30.1 \mathrm{~km}$ for Erh-jen River. Water depths of the stations ranged from 0.4 to $6.7 \mathrm{~m}$. The upper $15 \mathrm{~cm}$ of the surface sediments were sampled from the sampling sites using a boat with a Birge-Ekman sediment grabber in areas of low flow velocity $(<0.3 \mathrm{~m} / \mathrm{s})$. Immediately after collection, sediments were preserved in deep freeze in order to avoid degradation.

\subsection{Extraction and cleanup}

Homogenized subsamples were freeze-dried and OCPs were extracted with Soxhlet apparatus. A $10 \mathrm{~g}$ sediment was placed into a thimble filter and OCP residues in sediments were extracted with $250 \mathrm{ml}$ hexane for $24 \mathrm{~h}$ at a rate of $10-12$ cycles/ $\mathrm{h}$. The extract was then preconcentrated to $2-3 \mathrm{ml}$ on a rotary evaporator. The extract was further treated with activated copper powder to remove sulfur compounds. A 2 g Florisil SPE cartridge was used to cleanup the extracts. Sodium sulfate (ca. $1.0 \mathrm{~cm}$ ) was added to a Florisil SPE cartridge. The cartridge was washed with $6 \mathrm{ml}$ petroleum ether-ethyl ether $(95+5)$ at a rate of $5 \mathrm{ml} / \mathrm{min}$ and then the organochlorine pesticides were eluted with $12 \mathrm{ml}$ petroleum ether-ethyl ether $(95+5)$ at a rate of $2 \mathrm{ml} / \mathrm{min}$. The elutes were concentrated to about $1-2 \mathrm{ml}$ on a rotary evaporator and then transferred to $10 \mathrm{ml}$ glass tubes with small amounts of hexane. The solvent in the glass tube was entirely evaporated under a gentle stream of nitrogen and the precipitates were redissolved in $1 \mathrm{ml}$ hexane and analyzed with a gas chromatography (GC)electron capture detector (ECD) system.

\subsection{Analytical procedures}

The concentrations of OCPs in the extracts were monitored with GC equipped with an ECD and a PTE-5 fused silica capillary column $(30 \mathrm{~m}$ length $\times 0.32 \mathrm{~mm}$ inner diameter $\times 0.25 \mu \mathrm{m}$ film thickness, Supelco Inc., Co., Bellefonte, PA.). One $\mu$ l of each sample was injected into the GC system for separating the OCPs. Column temperature increased from 140 to $200^{\circ} \mathrm{C}$ at $15^{\circ} \mathrm{C} / \mathrm{min}$, held for $2 \mathrm{~min}$, and then programmed to $250^{\circ} \mathrm{C}$ at $2{ }^{\circ} \mathrm{Cl}$ $\mathrm{min}$, held for $2 \mathrm{~min}$. The temperatures of injector and detector were 250 and $300{ }^{\circ} \mathrm{C}$, respectively. Nitrogen gas was used as the carrier and make-up gases at flow rate of 

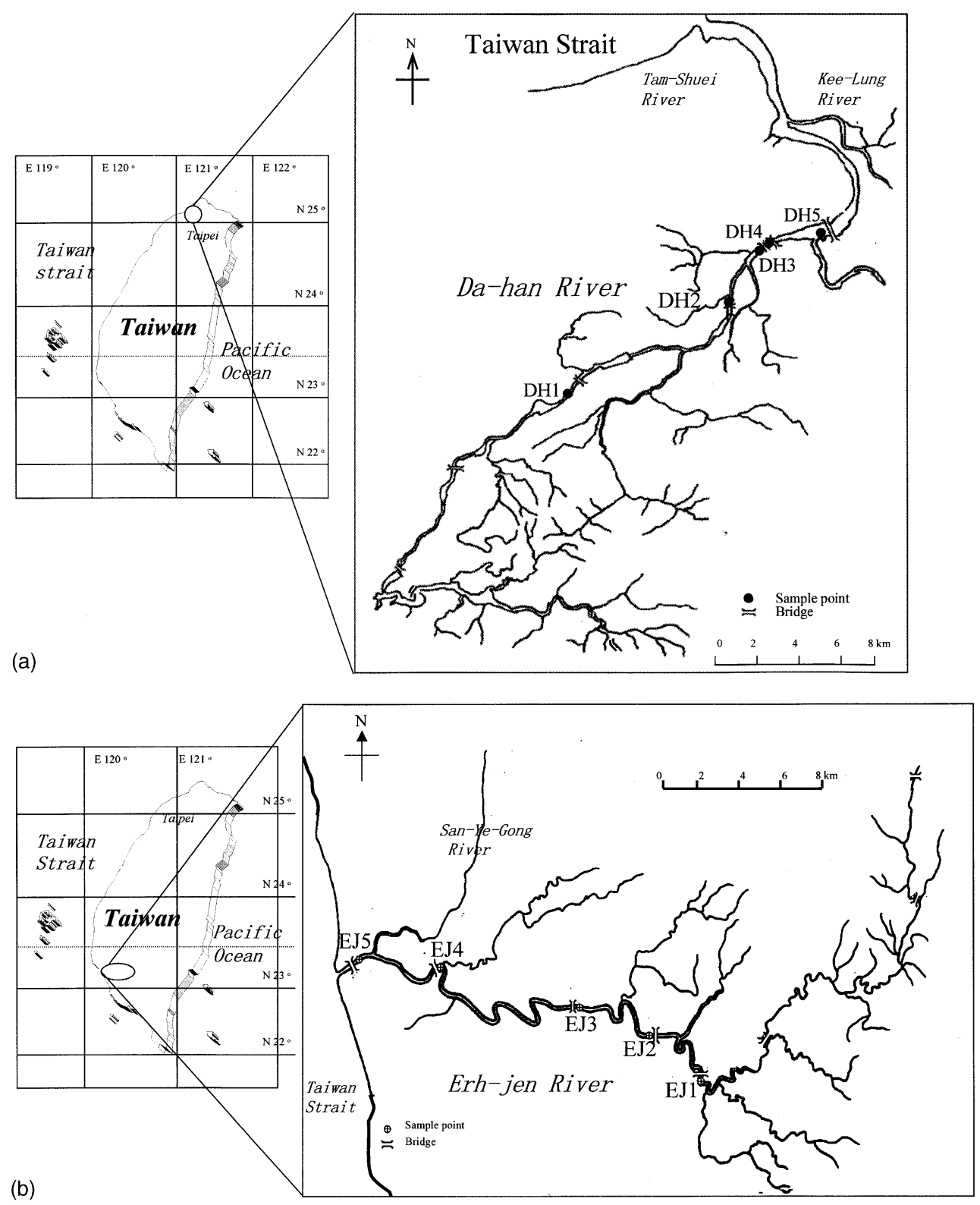

Fig. 1. The study areas and sampling locations in the selected rivers in Taiwan.

$1.73 \mathrm{ml} / \mathrm{min}$ (linear velocity, $25.2 \mathrm{~cm} / \mathrm{s}$ ) and $35.5 \mathrm{ml} / \mathrm{min}$, respectively. Pentachloronitrobenzene and decachlorobiphenyl were used as the internal standards. Also, identified peaks were checked by GC-ECD with SPB608 fused silica capillary column $(30 \mathrm{~m}$ length $\times 0.53$ $\mathrm{mm}$ inner diameter $\times 0.5 \mu \mathrm{m}$ film thickness, Supelco Inc., Co., Bellefonte, PA). The residues of OCPs were determined by comparing the peak areas of the samples and the calibration curves of the standards. The correlation coefficients $(R)$ of calibration curves of OCPs were all greater than 0.998 .
Oxidation-reduction potential (ORP), volatile suspended solid (VSS), total organic carbon (TOC), water content and particle size distribution of sediments were also analyzed. ORP was determined with an Orion EA 920 expandable ion analyzer (Orion Research Inc., Boston., MA.) by using an Orion model 97-78-00 Pt redox electrode. The values were expressed in terms of the ORPs of the samples relative to the Pt redox electrode and were read out until the potential changed was less than $0.5 \mathrm{mV} / \mathrm{min}$. Water content and VSS were determined by the weight loss at $103 \pm 2{ }^{\circ} \mathrm{C}$ and $550 \pm 50{ }^{\circ} \mathrm{C}$, 
Table 1

The recoveries, MDLs, and the analyzed results of CRM standards (840-050) of OCPs in sediments

\begin{tabular}{lcccc}
\hline Pesticides & Recovery (\%) & MDLs (ng/g dry weight) & \multicolumn{2}{c}{ CRM standard (mg/kg) } \\
\cline { 3 - 5 } & & & Certified value & Analyzed value \\
\hline$\alpha$-HCH & 85.0 & 0.12 & $-{ }^{\text {a }}$ & - \\
$\beta$-HCH & 94.4 & 0.35 & - & 470.6 \\
$\gamma$-HCH & 83.1 & 0.25 & - & - \\
$\delta$-HCH & 99.9 & 0.11 & - & - \\
Heptachlor & 92.0 & 0.15 & 18.04 & 19.18 \\
Aldrin & 92.2 & 0.05 & - & - \\
Heptachlor epoxide & 96.9 & 0.15 & 1464.3 & 1232.6 \\
Endosulfan I & 90.1 & 0.08 & 1519.6 & 1269.6 \\
$p, p^{\prime}$-DDE & 88.6 & 0.12 & 1862.5 & 1693.9 \\
Dieldrin & 98.9 & 0.12 & 62.15 & 67.7 \\
Endrin & 121.1 & 0.22 & 1128.2 & 1284.3 \\
Endosulfan II & 96.2 & 0.16 & 1530.6 & 1989.8 \\
$p, p^{\prime}$-DDD & 117.7 & 0.18 & - & - \\
Endosulfan sulfate & 85.2 & 0.13 & 1060.1 & 1067.7 \\
$p, p^{\prime}$-DDT & 116.4 & 0.18 & - & - \\
Endrin ketone & 69.5 & 0.13 & - & - \\
Methoxychlor & 129.4 & 0.30 & & \\
\hline
\end{tabular}

${ }^{\mathrm{a}}$ Not available.

respectively. Moreover, ampule TOC concentrations of sediment particles were obtained by a model 700 TOC analyzer using wet oxidation method (O.I. Corporation, Texas).

\subsection{Quality assurance}

For every set of 10 samples, a procedural blank and spike sample consisting of all reagents was run to check for interference and cross contamination. The method detection limits (MDLs) of OCPs were determined as the concentrations of analytes in a sample that gives rise to a peak with a signal-to-noise ratio $(S / N)$ of 3 . The OCP recoveries were determined relative to the ratio of direct injection of extract and the working standards prepared in hexane. Also, the quality of the analytical data was assured using the CRM 804-050 soil standard. Table 1 illustrates the recoveries and MDLs of OCPs. The recoveries and MDLs of OCPs ranged from $69.5 \%$ to $129.4 \%$ and $0.05-0.35 \mathrm{ng} / \mathrm{g}$ dry sediment, respectively. Moreover, the average analyzed concentrations of OCPs in CRM sample were in the range of $19.2-1989.8 \mathrm{mg} / \mathrm{kg}$, which corresponding to the recoveries of $84-130 \%$.

\section{Results and discussion}

\subsection{Characteristics of sediments}

Table 2 illustrates the basic physico-chemical parameters of sediments collected from Da-han and Erhjen Rivers. These parameters included ORP, VSS, TOC, water content and particle size distribution. The char- acteristics of sediments were site-depended. The ORP values ranged from 184 to $-372 \mathrm{mV}$ and from -59 to $-269 \mathrm{mV}$ for Da-han and Erh-jen Rivers, respectively. These measured OPR values reflect that the collected sediments were mainly under anaerobic conditions (Parsons and Barrio-Lage, 1985). The distributions of particle sizes in sediments from Da-han and Erh-jen Rivers were also different. The particle sizes in Da-han River ranged mainly from 180 to $300 \mu \mathrm{m}$, while smallsize particles $(8-37 \mu \mathrm{m})$ were dominant in Erh-jen River. Also, the TOC contents of sediments ranged from 0.51 to $7.86 \mathrm{mg} \mathrm{C} / \mathrm{g}$ and from 1.78 to $45.21 \mathrm{mg} \mathrm{C} / \mathrm{g}$ for Da-han River, and Erh-jen River, respectively. It is clear that Erh-jen River was composed of fine particles and had high organic contents in the sediments. This observation is consistent with other studies, which demonstrated that fine particles can retain large amounts of organic compounds and pose a high pollution potency (Sarkar et al., 1997). Moreover, the VSS contents of the sediments ranged from $1.07 \%$ to $2.5 \%$ and from $0.71 \%$ to $3.0 \%$ for Da-han and Erh-jen Rivers, respectively. A positive correlation $\left(r^{2}=0.692\right)$ between VSS and TOC in sediments was established, depicting that the sediment was contaminated with organic compounds (Fig. 2).

\subsection{Concentration profiles of OCPs}

Tables 3 and 4 illustrate the concentrations of OCP residues in surface sediments from Da-han and Erh-jen Rivers, respectively. Concentrations of OCPs in sediments from Da-han River were $<0.12-4.94 \mathrm{ng} / \mathrm{g}$ d.w. for $\sum \mathrm{HCH},<0.05-0.15 \mathrm{ng} / \mathrm{g}$ d.w. for aldrin, $<0.12-5.8 \mathrm{ng} / \mathrm{g}$ d.w. for dieldrin, $<0.08-3.78 \mathrm{ng} / \mathrm{g}$ d.w. for endosulfan, 
Table 2

The physicochemical properties of surface sediments collected from the selected rivers in Taiwan

\begin{tabular}{lllllll}
\hline $\begin{array}{l}\text { Sampling } \\
\text { stations* }\end{array}$ & $\begin{array}{l}\text { Water depth } \\
(\mathrm{m})\end{array}$ & $\begin{array}{l}\text { ORP value } \\
(\mathrm{mV})\end{array}$ & VSS $(\%)$ & $\begin{array}{l}\text { Water } \\
\text { content }(\%)\end{array}$ & $\begin{array}{l}\text { TOC }(\mathrm{mg} \text { C/g) } \\
\text { DH-1 }\end{array}$ & $\begin{array}{l}\text { Particle size } \\
\text { distribution }(\mu \mathrm{m})\end{array}$ \\
DH-2 & $1.9-6.7$ & $(184)-(-184)$ & $1.56-2.50$ & $33.2-47.1$ & $4.72-7.88$ & $8-37$ \\
DH-3 & $0.9-2.2$ & $(-181)-(-220)$ & $1.52-1.82$ & $26.2-31.9$ & $1.76-5.32$ & $37-300$ \\
DH-4 & $2.0-4.5$ & $(-18)-(-112)$ & $1.35-1.57$ & $24.9-27.0$ & $1.62-3.23$ & $180-300$ \\
DH-5 & $1.9-6.5$ & $(-172)-(-372)$ & $1.36-2.44$ & $23.9-51.9$ & $1.49-5.98$ & $8-300$ \\
EJ-1 & $0.4-1.0$ & $(-59)-(-185)$ & $1.07-1.59$ & $26.2-30.3$ & $0.51-5.21$ & $105-300$ \\
EJ-2 & $0.6-1.8$ & $(-105)-(-234)$ & $1.29-1.94$ & $26.2-35.7$ & $2.82-6.94$ & $8-37$ \\
EJ-3 & $0.5-3.0$ & $(-234)-(-255)$ & $0.49-1.89$ & $25.4-39.6$ & $1.79-3.59$ & $8-180$ \\
EJ-4 & $1.8-2.1$ & $(-255)-(-269)$ & $0.71-2.71$ & $47.9-50.3$ & $2.2-11.15$ & $4-180$ \\
EJ-5 & $2.5-3.7$ & $(-179)-(-269)$ & $0.82-3.0$ & $30.3-72.7$ & $9.03-45.21$ & $2-37$ \\
\hline
\end{tabular}

${ }^{*}$ Five sampling stations along each river were selected and four samples from each station were collected.

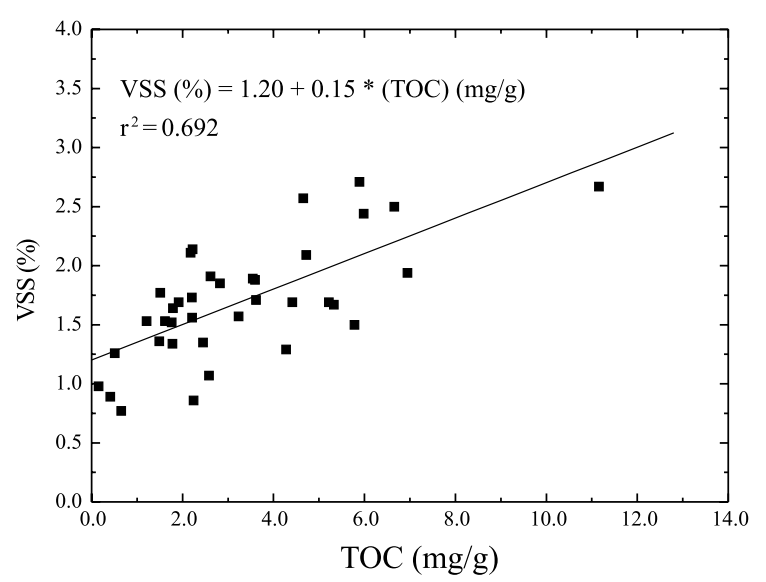

Fig. 2. The relationship between ampule TOC $(\mathrm{mgC} / \mathrm{g})$ and VSS $(\%)$ in sediments collected from the selected rivers.

$<0.18-2.64 \mathrm{ng} / \mathrm{g}$ d.w. for $p, p^{\prime}$-DDT and $<0.3-2.85 \mathrm{ng} / \mathrm{g}$ d.w. for methoxychlor. Several biological metabolites of the parent OCPs were also detected. The concentrations were $0.32-2.39 \mathrm{ng} / \mathrm{g}$ d.w. for endrin aldehyde, $0.62-3.18$ $\mathrm{ng} / \mathrm{g}$ d.w. for endosulfan sulfate, $0.51-3.89 \mathrm{ng} / \mathrm{g}$ d.w. for $p, p^{\prime}$-DDE and 0.56-3.34 ng/g d.w. for $p, p^{\prime}$-DDD.

Concentrations of OCP residues in sediments from Erh-jen River were higher than those from Da-han River. As illustrated in Table 4, concentrations of OCPs ranged from $<0.35$ to $14.1 \mathrm{ng} / \mathrm{g}$ d.w. for $\beta-\mathrm{HCH},<0.12$ to $1.29 \mathrm{ng} / \mathrm{g}$ d.w. for dieldrin, $<0.08$ to $6.27 \mathrm{ng} / \mathrm{g}$ d.w. for endosulfan, $<0.12$ to $1.69 \mathrm{ng} / \mathrm{g}$ d.w. for $p, p^{\prime}$-DDE, $<0.18$ to $3.9 \mathrm{ng} / \mathrm{g}$ d.w. for $p, p^{\prime}$-DDD,$<0.18$ to $5.57 \mathrm{ng} / \mathrm{g}$ d.w. for $p, p^{\prime}$-DDT and $<0.3$ to $7.39 \mathrm{ng} / \mathrm{g}$ d.w. for methoxychlor. This may be due to the high organic contents of the sediment particles in Erh-jen River. Several studies have depicted that the contamination of hydrophobic organic compounds in sediments is dependent on the chemical properties of the ecosystem, the partition coefficients of individual compounds and the organic contents of sediment particles (McKenzie-Smith et al., 1994; Glynn et al., 1995). A similar distribution pattern of OCPs in sediments from the selected rivers was obtained when the concentrations of OCP residues were normalized to TOC contents. Table 5 illustrates the concentration ranges, medians and mean values of OCPs in the selected rivers based on TOC concentrations. The total OCP residues in sediments from Da-han River ranged from 0.21 to $7.42 \mu \mathrm{g} / \mathrm{g}$ TOC with the mean value of $2.34 \mu \mathrm{g} / \mathrm{g}$ TOC. Also, $\sum \mathrm{HCH}, \sum$ cyclodiene and $\sum D D T$ concentrations ranged from ND to 2.08 , from $\mathrm{ND}$ to 4.51 and from 0.06 to $2.91 \mu \mathrm{g} / \mathrm{g}$ TOC, respectively. The normalized OCP concentrations in sediments collected from Erh-jen River was only slightly higher than that from Da-han River. The measured $\sum \mathrm{HCH}$ ranged from ND to $3.47 \mu \mathrm{g} / \mathrm{g}$ TOC with the mean value of $1.03 \mu \mathrm{g} / \mathrm{g}$ TOC. Although this value is 2-fold higher than that in Da-han River, the concentration ranges and mean values of $\sum$ DDT and $\sum$ cyclodiene obtained from Erh-jen River were similar to those from Da-han River. Also, the total concentrations of OCPs in Erh-jen River ranged from 0.08 to $8.20 \mu \mathrm{g} / \mathrm{g}$ TOC with the mean concentration of $2.67 \mu \mathrm{g} / \mathrm{g}$ TOC, which is similar to that in Da-han River. This result reflects that the contamination of OCPs in sediments from the selected rivers in Taiwan may be partly from the same pollution sources.

Fig. 3 illustrates the detection frequencies of OCPs in sediments collected from the selected rivers. Among the OCPs detected in Da-han River, endosulfan sulfate was the most frequent found compound in sediment $(60 \%)$, followed by $p, p^{\prime}$-DDE $(55 \%)$ and dieldrin $(55 \%)$. Also, high detection frequencies of $p, p^{\prime}$-DDD and $p, p^{\prime}$-DDT were demonstrated. This result shows that DDTs were the most dominant compounds in the sediments from Da-han River. Similar to the results in Da-han River, high detection frequencies of $\beta-\mathrm{HCH}, p, p^{\prime}$-DDD, endosulfan sulfate and $p, p^{\prime}$-DDE were observed in sediments from Erh-jen River. The detection frequencies 
Table 3

Concentrations of OCP residues in surface sediment of the Da-han River

\begin{tabular}{|c|c|c|c|c|c|c|c|c|c|c|c|c|c|c|c|c|c|}
\hline \multirow[t]{2}{*}{ Sample } & \multicolumn{17}{|c|}{ OCPs (ng/g of dry sediment) ${ }^{\mathrm{a}}$} \\
\hline & $\alpha-\mathrm{BHC}$ & $\beta$-BHC & Hept. & $\begin{array}{l}\text { Hept. } \\
\text { epoxide }\end{array}$ & Aldrin & $\begin{array}{l}\text { Diel- } \\
\text { drin }\end{array}$ & Endrin & Endo. I & Endo. II & $\begin{array}{l}\text { Endo. } \\
\text { sulfate }\end{array}$ & $\begin{array}{l}\text { Endrin } \\
\text { alde- } \\
\text { hyde }\end{array}$ & $\begin{array}{l}\text { Endrin } \\
\text { ketone }\end{array}$ & DDE & DDD & DDT & $\begin{array}{l}\text { Meth- } \\
\text { oxy. }\end{array}$ & $\sum \mathrm{OCP}$ \\
\hline DH-101 & 1.96 & $<0.35$ & $<0.15$ & $<0.05$ & 0.4 & $<0.22$ & $<0.15$ & $<0.08$ & $<0.16$ & $<0.13$ & $<0.06$ & $<0.13$ & 1.33 & 0.69 & 0.75 & $<0.3$ & 5.13 \\
\hline DH-201 & 3.74 & $<0.35$ & $<0.15$ & 0.08 & $<0.12$ & $<0.22$ & $<0.15$ & $<0.08$ & $<0.16$ & $<0.13$ & 0.32 & $<0.13$ & $<0.12$ & $<0.18$ & 1.03 & $<0.3$ & 5.17 \\
\hline DH-301 & 1.31 & $<0.35$ & $<0.15$ & $<0.05$ & $<0.12$ & $<0.22$ & $<0.15$ & $<0.08$ & 0.18 & $<0.13$ & $<0.06$ & $<0.13$ & $<0.12$ & $<0.18$ & 0.21 & $<0.3$ & 1.7 \\
\hline DH-401 & 4.32 & $<0.35$ & $<0.15$ & $<0.05$ & 0.29 & $<0.22$ & $<0.15$ & 2.41 & 1.36 & 2.21 & $<0.06$ & $<0.13$ & 1.5 & $<0.18$ & 1.76 & $<0.3$ & 13.85 \\
\hline DH-501 & $<0.12$ & $<0.35$ & $<0.15$ & $<0.05$ & 3.16 & $<0.22$ & $<0.15$ & $<0.08$ & $<0.16$ & 0.88 & $<0.06$ & $<0.13$ & $<0.12$ & $<0.18$ & 0.32 & $<0.3$ & 4.36 \\
\hline DH-102 & 4.55 & 0.39 & $<0.15$ & 0.15 & 5.8 & $<0.22$ & $<0.15$ & $<0.08$ & $<0.16$ & $<0.13$ & $<0.06$ & $<0.13$ & 3.89 & $<0.18$ & $<0.18$ & $<0.3$ & 14.78 \\
\hline DH-202 & $<0.12$ & $<0.35$ & $<0.15$ & $<0.05$ & 0.18 & $<0.22$ & $<0.15$ & $<0.08$ & 0.03 & $<0.13$ & $<0.06$ & $<0.13$ & 2.29 & $<0.18$ & 0.83 & $<0.3$ & 3.33 \\
\hline DH-302 & $<0.12$ & $<0.35$ & $<0.15$ & $<0.05$ & $<0.12$ & $<0.22$ & $<0.15$ & $<0.08$ & $<0.16$ & $<0.13$ & $<0.06$ & $<0.13$ & $<0.12$ & $<0.18$ & 0.47 & $<0.3$ & 0.47 \\
\hline DH-402 & $<0.12$ & $<0.35$ & $<0.15$ & $<0.05$ & 0.89 & $<0.22$ & $<0.15$ & $<0.08$ & $<0.16$ & $<0.13$ & $<0.06$ & $<0.13$ & 0.46 & $<0.18$ & $<0.18$ & $<0.3$ & 1.35 \\
\hline DH-502 & $<0.12$ & $<0.35$ & $<0.15$ & $<0.05$ & $<0.12$ & $<0.22$ & $<0.15$ & $<0.08$ & $<0.16$ & $<0.13$ & $<0.06$ & $<0.13$ & $<0.12$ & $<0.18$ & $<0.18$ & 0.2 & 0.2 \\
\hline DH-103 & $<0.12$ & $<0.35$ & $<0.15$ & $<0.05$ & 0.82 & $<0.22$ & $<0.15$ & 0.69 & $<0.16$ & 0.8 & $<0.06$ & $<0.13$ & 0.51 & 0.56 & $<0.18$ & 0.52 & 3.9 \\
\hline DH-203 & 0.73 & $<0.35$ & 0.58 & $<0.05$ & $<0.12$ & $<0.22$ & $<0.15$ & 0.71 & $<0.16$ & 0.62 & $<0.06$ & $<0.13$ & 1.52 & $<0.18$ & $<0.18$ & $<0.3$ & 4.16 \\
\hline DH-303 & $<0.12$ & $<0.35$ & $<0.15$ & $<0.05$ & $<0.12$ & 0.56 & $<0.15$ & $<0.08$ & 0.51 & 2.27 & 0.68 & $<0.13$ & $<0.12$ & 1.5 & 1.57 & 0.76 & 7.85 \\
\hline DH-403 & $<0.12$ & $<0.35$ & 1.15 & $<0.05$ & $<0.12$ & $<0.22$ & $<0.15$ & $<0.08$ & $<0.16$ & 3.18 & 2.39 & $<0.13$ & $<0.12$ & 1.36 & 2.26 & 0.72 & 11.06 \\
\hline DH-503 & 1.44 & 1.08 & 0.54 & $<0.05$ & $<0.12$ & $<0.22$ & $<0.15$ & $<0.08$ & $<0.16$ & 2.03 & $<0.06$ & $<0.13$ & $<0.12$ & 3.34 & $<0.18$ & $<0.3$ & 8.43 \\
\hline DH-104 & $<0.12$ & $<0.35$ & 1.23 & $<0.05$ & 0.8 & $<0.22$ & $<0.15$ & 1.08 & 0.62 & 0.89 & 0.66 & 0.57 & 0.72 & 1.07 & $<0.18$ & $<0.3$ & 7.64 \\
\hline DH-204 & $<0.12$ & $<0.35$ & $<0.15$ & $<0.05$ & $<0.12$ & $<0.22$ & $<0.15$ & 1.54 & 0.85 & 2.16 & $<0.06$ & $<0.13$ & 0.63 & 0.91 & $<0.18$ & $<0.3$ & 6.09 \\
\hline DH-304 & $<0.12$ & 0.73 & 0.63 & $<0.05$ & 0.59 & $<0.22$ & $<0.15$ & $<0.08$ & $<0.16$ & 1.67 & 0.56 & $<0.13$ & $<0.12$ & 0.64 & $<0.18$ & $<0.3$ & 4.82 \\
\hline DH-404 & 1.9 & $<0.35$ & 1.57 & $<0.05$ & 0.72 & $<0.22$ & $<0.15$ & $<0.08$ & $<0.16$ & 2.66 & 1.07 & $<0.13$ & 1.22 & 1.65 & 2.64 & $<0.3$ & 13.43 \\
\hline DH-504 & $<0.12$ & 0.67 & $<0.15$ & $<0.05$ & 0.52 & $<0.22$ & $<0.15$ & 0.57 & $<0.16$ & 1.38 & 0.89 & 1.34 & 0.71 & 1.41 & $<0.18$ & 2.85 & 10.34 \\
\hline
\end{tabular}

${ }^{\mathrm{a}}$ Hept.: heptachlor; Endo.: endosulfan, Methoxy.: methoxychlor. 
Table 4

Concentrations of OCP residues in surface sediment of the Erh-jen River

\begin{tabular}{|c|c|c|c|c|c|c|c|c|c|c|c|c|c|c|c|c|c|}
\hline \multirow[t]{2}{*}{ Sample } & \multicolumn{17}{|c|}{ OCPs (ng/g of dry sediment) ${ }^{\mathrm{a}}$} \\
\hline & $\alpha-\mathrm{BHC}$ & $\beta-\mathrm{BHC}$ & Hept. & $\begin{array}{l}\text { Hept. } \\
\text { epoxide }\end{array}$ & Aldrin & $\begin{array}{l}\text { Diel- } \\
\text { drin }\end{array}$ & Endrin & Endo. I & Endo. II & $\begin{array}{l}\text { Endo. } \\
\text { sulfate }\end{array}$ & $\begin{array}{l}\text { Endrin } \\
\text { alde- } \\
\text { hyde }\end{array}$ & $\begin{array}{l}\text { Endrin } \\
\text { ketone }\end{array}$ & DDE & DDD & DDT & $\begin{array}{l}\text { Meth- } \\
\text { oxy. }\end{array}$ & $\sum \mathrm{OCP}$ \\
\hline EJ-101 & $<0.12$ & 0.57 & $<0.15$ & $<0.24$ & $<0.05$ & $<0.12$ & $<0.22$ & $<0.08$ & $<0.16$ & $<0.13$ & $<0.06$ & $<0.13$ & $<0.12$ & $<0.18$ & $<0.18$ & $<0.3$ & 0.57 \\
\hline EJ-201 & $<0.12$ & $<0.35$ & $<0.15$ & $<0.24$ & $<0.05$ & $<0.12$ & $<0.22$ & $<0.08$ & $<0.16$ & $<0.13$ & 0.89 & $<0.13$ & $<0.12$ & $<0.18$ & 2.35 & $<0.3$ & 3.24 \\
\hline EJ-301 & $<0.12$ & 0.53 & $<0.15$ & $<0.24$ & $<0.05$ & $<0.2$ & $<0.22$ & $<0.08$ & $<0.16$ & $<0.13$ & $<0.06$ & $<0.13$ & $<0.12$ & $<0.18$ & 0.09 & 0.57 & 1.19 \\
\hline EJ-401 & $<0.12$ & 5.35 & $<0.15$ & $<0.24$ & $<0.05$ & $<0.12$ & $<0.22$ & $<0.08$ & $<0.16$ & 1.27 & $<0.06$ & $<0.13$ & $<0.12$ & $<0.18$ & $<0.18$ & $<0.3$ & 6.62 \\
\hline EJ-501 & $<0.12$ & 2.27 & $<0.15$ & $<0.24$ & $<0.05$ & 1.29 & $<0.22$ & $<0.08$ & $<0.16$ & $<0.13$ & $<0.06$ & $<0.13$ & 0.38 & $<0.18$ & 0.57 & $<0.3$ & 4.51 \\
\hline EJ-102 & 0.97 & 5.93 & $<0.15$ & $<0.24$ & $<0.24$ & $<0.12$ & 0.64 & $<0.08$ & $<0.16$ & $<0.13$ & $<0.06$ & $<0.13$ & 0.28 & $<0.18$ & 1.44 & $<0.3$ & 9.26 \\
\hline EJ-202 & $<0.12$ & 2.61 & $<0.15$ & $<0.24$ & $<0.05$ & $<0.12$ & 0.23 & 0.63 & $<0.16$ & 0.21 & $<0.06$ & $<0.13$ & $<0.12$ & 0.25 & 0.3 & $<0.3$ & 4.23 \\
\hline EJ-302 & $<0.12$ & 5.09 & $<0.15$ & $<0.24$ & $<0.05$ & $<0.12$ & $<0.22$ & 0.5 & $<0.16$ & $<0.13$ & 0.02 & $<0.13$ & $<0.12$ & 2.28 & 0.71 & $<0.3$ & 8.60 \\
\hline EJ-402 & $<0.12$ & 7.15 & $<0.15$ & $<0.24$ & $<0.05$ & 0.17 & $<0.22$ & 0.39 & 2.12 & $<0.13$ & $<0.06$ & $<0.13$ & 0.4 & 0.45 & 0.29 & $<0.3$ & 10.97 \\
\hline EJ-502 & $<0.12$ & 14.1 & 5.61 & $<0.24$ & $<0.05$ & $<0.12$ & $<0.22$ & 1.71 & 0.71 & $<0.13$ & 0.2 & $<0.13$ & $<0.2$ & 0.26 & 1.08 & $<0.3$ & 23.67 \\
\hline EJ-103 & 1.17 & 3.77 & 0.64 & $<0.24$ & $<0.05$ & $<0.12$ & $<0.22$ & 2.12 & $<0.16$ & 1.25 & 0.64 & 1.77 & 0.66 & 2.7 & $<0.18$ & 0.74 & 15.46 \\
\hline EJ-203 & $<0.12$ & $<0.35$ & $<0.15$ & $<0.24$ & $<0.05$ & $<0.12$ & $<0.22$ & $<0.08$ & $<0.16$ & 0.96 & $<0.06$ & $<0.13$ & $<0.12$ & 0.75 & $<0.18$ & 1.14 & 2.85 \\
\hline EJ-303 & 0.84 & 4.4 & 0.51 & $<0.24$ & $<0.05$ & 0.58 & $<0.22$ & 2.3 & $<0.16$ & 0.72 & 1.99 & 1.02 & 0.75 & 3.9 & $<0.18$ & 1.23 & 18.24 \\
\hline EJ-403 & 1.11 & 3.1 & 0.95 & $<0.24$ & $<0.05$ & 0.53 & $<0.22$ & $<0.08$ & $<0.16$ & 1.58 & $<0.06$ & $<0.13$ & 1.69 & 1.55 & 5.57 & $<0.3$ & 16.08 \\
\hline EJ-503 & 1.5 & $<0.35$ & 0.6 & $<0.24$ & $<0.05$ & 0.77 & $<0.22$ & 3.26 & 3.01 & 0.89 & 1.42 & $<0.13$ & 1.39 & 1.09 & $<0.18$ & $<0.3$ & 13.93 \\
\hline EJ-104 & 1.36 & 1.63 & $<0.15$ & $<0.24$ & $<0.05$ & 1.09 & $<0.22$ & 1.07 & 0.93 & 1.12 & 0.61 & $<0.13$ & 0.65 & 1.14 & $<0.18$ & 1.71 & 11.31 \\
\hline EJ-204 & 1.37 & 1.48 & $<0.15$ & $<0.24$ & $<0.05$ & 0.98 & $<0.22$ & 0.52 & $<0.16$ & 1.52 & $<0.06$ & 1.76 & 0.86 & 3.49 & $<0.18$ & 7.39 & 19.37 \\
\hline EJ-304 & 1.2 & 5.02 & $<0.15$ & $<0.24$ & $<0.05$ & 0.58 & $<0.22$ & 1.13 & $<0.16$ & 0.6 & $<0.06$ & $<0.13$ & 0.67 & 1.9 & 1 & $<0.3$ & 12.1 \\
\hline EJ-404 & 1.29 & 2.83 & 0.65 & $<0.24$ & $<0.05$ & $<0.12$ & $<0.22$ & $<0.08$ & $<0.16$ & 1.72 & $<0.06$ & $<0.13$ & 1.1 & 1.66 & 1.04 & 0.71 & 11 \\
\hline EJ-504 & 1.18 & $<0.35$ & $<0.15$ & $<0.24$ & $<0.05$ & $<0.12$ & $<0.22$ & 1.09 & $<0.16$ & 0.37 & 0.66 & 0.61 & 0.78 & $<0.18$ & $<0.18$ & $<0.3$ & 4.69 \\
\hline
\end{tabular}

${ }^{\mathrm{a}}$ Hept.: heptachlor; Endo.: endosulfan, Methoxy.: methoxychlor. 
Table 5

Concentration ranges, medians and mean values of OCP residues in surface sediments collected from Da-han and Erh-jen Rivers

\begin{tabular}{|c|c|c|c|c|c|c|}
\hline \multirow[t]{2}{*}{ OCPs } & \multicolumn{3}{|c|}{ Da-han river $(\mu \mathrm{g} / \mathrm{g}$ TOC) } & \multicolumn{3}{|c|}{ Erh-jen River ( $\mu \mathrm{g} / \mathrm{g}$ TOC) } \\
\hline & Range & Median & Mean & Range & Median & Mean \\
\hline$\sum \mathrm{OCP}$ & $0.21-7.42$ & 1.73 & 2.34 & $0.08-8.20$ & 2.03 & 2.67 \\
\hline$\sum \mathrm{HCH}$ & ND-2.08 & 0.13 & 0.39 & ND-3.47 & 0.70 & 1.03 \\
\hline$\sum$ Cyclodiene & ND-4.51 & 0.87 & 1.05 & ND-5.8 & 0.53 & 0.92 \\
\hline$\sum \mathrm{DDT}$ & $0.06-2.91$ & 0.43 & 0.90 & ND-2.03 & 0.50 & 0.72 \\
\hline
\end{tabular}

ND: not detected.

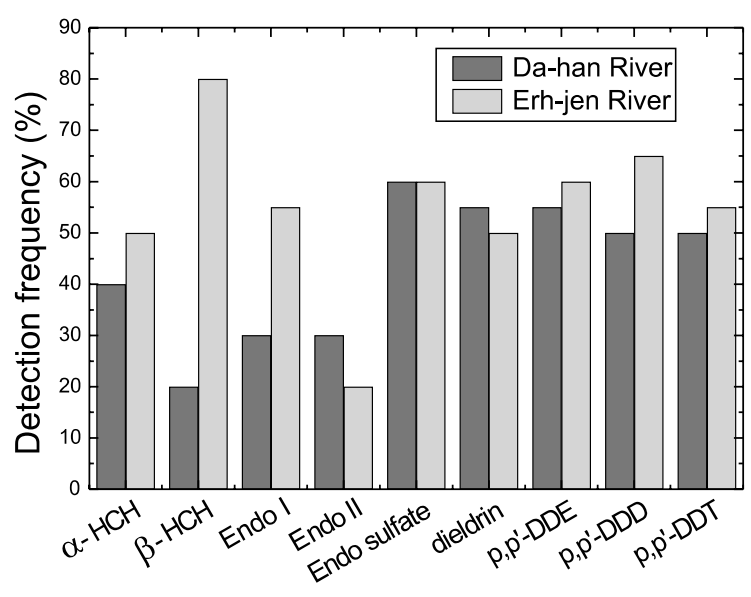

Fig. 3. The detection frequencies of OCPs in the sediments collected from Da-han and Erh-jen Rivers, Taiwan. The results are the means of the OCPs from the five sampling stations and four sampling times in each river.

were $80 \%, 65 \%, 60 \%$ and $60 \%$, respectively. These results clearly show that DDTs and HCHs were the main OCPs used in Taiwan.

\subsection{Characteristics of OCP contamination in sediments}

The relative concentrations of the parent DDT compound and its metabolites can provide useful information on the pollution source. The compound $p, p^{\prime}$ DDT is the active ingredient of the DDT pesticides and typically makes up approximately $80 \%$ of the technical formulation (Bopp et al., 1982; Hendy and Peake, 1996). Fig. 4 illustrates the ratios of DDD/DDE and (DDE + DDD) $/ \sum$ DDT in the sediments from Da-han and Erhjen Rivers. Ratios of (DDE + DDD)/ $\sum$ DDT in sediments ranged from 0.37 to 1.0 . Since ratio of (DDE + DDD) $/ \sum$ DDT $>0.5$ is reported to be subjected to long-term weathering (Hites and Day, 1992), results obtained in this study indicate that the DDT compounds in sediments may be mainly derived from DDT-treated aged and weathered agricultural soils. Also, the ratios of DDD/DDE ranged from 0.24 to 1.99 and from 0.78 to

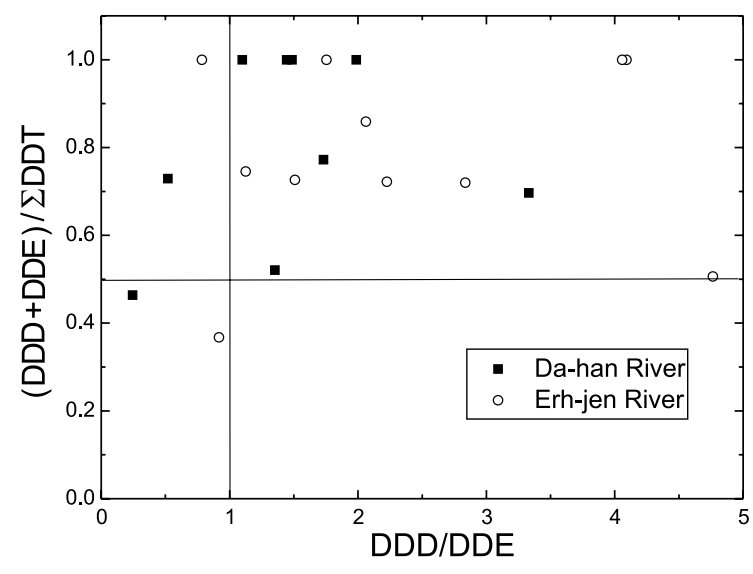

Fig. 4. The relationship between DDD/DDE and (DDE + DDD) / $\sum$ DDT in sediments from Da-han and Erh-jen Rivers.

5.20 for Da-han and Erh-jen Rivers, respectively. Most of the ratios are greater than unity. This means that the total DDT found in sediments from the selected rivers is dominated by $p, p^{\prime}$-DDD, the product of anaerobic degradation of $p, p^{\prime}$-DDT. This result is consistent with the measured ORP values ( -372 to $184 \mathrm{mV}$ ), suggesting that the input of DDT compounds to the rivers was via the weathered agricultural soils and was retained under anaerobic conditions within the sediment in Taiwan rivers.

The frequency of detection of $\mathrm{HCH}$ compounds in environmental samples showed that the contamination of $\mathrm{HCH}$ was also widespread in Taiwan rivers. Recent studies also show that the contamination of $\mathrm{HCH}$ isomers is a serious problem worldwide (Fellin et al., 1996; Sarkar et al., 1997; Hong et al., 1999; Walker et al., 1999). HCH pesticide is an inexpensive insecticide and had been used for agricultural purpose to control the insects in fruit, grain and vegetable crops in Taiwan since 1950s. Technical-grade $\mathrm{HCH}$ consists principally of five isomers, $\alpha-\mathrm{HCH}(60-70 \%), \beta-\mathrm{HCH}(5-12 \%), \gamma-$ $\mathrm{HCH}(10-15 \%), \delta-\mathrm{HCH}(6-10 \%)$ and $\varepsilon-\mathrm{HCH}(3-4 \%)$ (Walker et al., 1999). The most often found isomers in the environment are $\alpha$-, $\beta$ - and $\gamma$-isomers. $\alpha$-HCH was found to be the dominant compound of $\mathrm{HCH}$ in the 
sediments from Da-han River. Since the catchment of Da-han River is a heavily urbanized area, the contamination of $\alpha-\mathrm{HCH}$ may be attributed to the long distance transport from other areas. Some OCPs such as endosulfan, heptachlor and $\mathrm{HCH}$ are still used in some developing countries around the tropical belt and may be transported through the atmosphere and gradually deposit in the river at higher latitudes. Oehme et al. (1996) measured the seasonal concentration changes of organochlorines in the European Arctic and found that longrange atmospheric transport from more polluted areas might lead to a significant concentration change in the Arctic air. It is estimated that the total global usage of technical grade $\mathrm{HCH}$ between 1948 and 1997 was around 10 million tons $(\mathrm{Li}, 1999)$. Recently, considerable unused stockpiles of technical-grade $\mathrm{HCH}$ was found in dump sites in Africa and Near East (FAO, 1998). Some of the containers have damaged and are leaking. Among the $\mathrm{HCH}$ isomers, $\alpha-\mathrm{HCH}$ is more likely to partition to the air and transport for a long distance. A study conducted in India examining the flux of $\mathrm{HCH}$ also indicated that most of the $\mathrm{HCH}$ applied annually was lost to the atmosphere (Takeoka et al., 1991). These results depict that $\alpha-\mathrm{HCH}$ may be mainly from the long-range transport (LRT). Since $\alpha-\mathrm{HCH}$ exhibits the most carcinogenic activity among $\mathrm{HCH}$ isomers, the contamination levels detected may pose a high ecotoxicity for aquatic organisms.

Different $\mathrm{HCH}$ contamination patterns for Erh-jen River were observed. The detection frequencies of $\alpha$ - and $\beta-\mathrm{HCH}$ were $50 \%$ and $80 \%$, respectively. The similar detection frequency of $\alpha-\mathrm{HCH}$ in the selected rivers shows that the LRT may be the major source of $\alpha-\mathrm{HCH}$ in Erh-jen River. Unlike the $\alpha-\mathrm{HCH}, \beta-\mathrm{HCH}$ is more lipophilic and is the predominant isomer in soils and animal tissue and fluids (Willett et al., 1998). Also, $\beta$ $\mathrm{HCH}$ is resistant to hydrolysis and environmental degradation. Since Erh-jen River is a strong agricultural sector in southern Taiwan, the abundance of the $\beta$ $\mathrm{HCH}$ may be attributed to the weathered soils, which is also consistent with the results of $\sum D D T$.

\section{Conclusions}

The results obtained in this study documents the first known analysis of OCP distributions in sediments collected from Da-han and Erh-jen Rivers, Taiwan. There still exist a variety of OCP residues in the river sediments in Taiwan. The total concentrations of OCPs in sediments ranged from 0.2 to 14.8 and 0.6 to $29.5 \mathrm{ng} / \mathrm{g}$ dry weight for Da-han and Erh-jen Rivers, respectively, which corresponds to $0.21-7.42$ and $0.08-8.20 \mu \mathrm{g} / \mathrm{g}$ TOC when normalized to TOC concentrations. DDTs and $\mathrm{HCH}$ sere the dominant OCPs in sediments from the selected rivers. Da-han River was mainly contaminated with $\alpha-\mathrm{HCH}$ and $p, p^{\prime}$-DDE, while the main pesticide residues in Erh-jen River were $\beta$-HCH and $p, p^{\prime}$-DDD. The detection frequencies of the metabolites were higher than those of parent compounds. This distribution pattern reflects the fact that the contamination of the collected sediments is mainly from LRT and weathered agricultural soils.

\section{Acknowledgements}

The authors would like to thank Environmental Protection Administration (EPA) and National Science Council, Taiwan, ROC for the financial supports under the Contract No. EPA-87-E3L1-03-02 and NSC 902621-Z-007-002.

\section{References}

Bopp, R.F., Simpson, H.J., Olsen, C.R., Trier, R.M., Kostyk, N., 1982. Chlorinated hydrocarbons and radionuclide chronologies in sediments of the Hudson River and Estuary, New York. Environ. Sci. Technol. 16, 666-676.

Brook, E.J., Moore, J.N., 1988. Particle-size and chemical control of $\mathrm{As}, \mathrm{Cd}, \mathrm{Cu}, \mathrm{Fe}, \mathrm{Mn}, \mathrm{Ni}, \mathrm{Pb}$, and $\mathrm{Zn}$ in bed sediment from the Clark Fork river, Montana (USA). Sci. Total Environ. 76, 247-266.

Doong, R.A., Lee, C.Y., 1999. Dietary intake and residues of organochlorine pesticides in foods from Hsinchu, Taiwan. J. AOAC Int. 82, 677-682.

Food and Agriculture Organization of the United Nations (FAO), 1998. Inventory of obsolete, unwanted and/or banned pesticides. FAO, Rome, Italy, Document GCP/ INT/650/NET.

Fellin, P., Barrie, L.A., Dougherty, D., Toom, D., Muir, D., Grift, N., Lockhart, L., Billeck, B., 1996. Air monitoring in the Arctic: results for selected persistent organic pollutant for 1992. Environ. Toxicol. Chem. 15, 253-261.

Glynn, P.W., Rumbold, D.G., Sendaker, S.C., 1995. Organochlorine pesticide residues in marine sediment and biota from the northern Florida reef tract. Mar. Pollut. Bull. 30, 397-402.

Gold-Bouchot, G., Silva-Herrera, T., Zapata-Perez, O., 1995. Organochlorine pesticide residues concentrations in Biota and Sediments from Rio Palizada, Mexico. Bull. Environ. Contam. Toxicol. 54, 554-561.

Hendy, E., Peake, B.M., 1996. Organochlorine pesticides in a dated sediment core from Mapua, Waimea Inlet, New Zealand. Mar. Pollut. Bull. 32, 751-754.

Hites, R.K., Day, H.R., 1992. Unusual persistence of DDT in some western USA soils. Bull. Environ. Contam. Toxicol. 48, 259-264.

Hong, H., Chen, W., Xu, L., Wang, X., Zhang, L., 1999. Distribution and fate of organochlorine pollutants in the Pearl River Estuary. Mar. Pollut. Bull. 39, 376-382. 
Li, Y.F., 1999. Global technical hexachlorocyclohexane usage and its contamination consequences in the environment: from 1948 to 1997. Sci. Total Environ. 232, 121-158.

McKenzie-Smith, K., Tiller, D., Allen, D., 1994. Organochlorine pesticide residues in water and sediments from the Ovens and King rivers, north-east Victoria, Australia. Arch. Environ. Contam. Toxicol. 26, 390-483.

Oehme, M., Haugen, J.E., Schlabach, M., 1996. Seasonal changes and relations between levels of organochlorines in Arctic ambient air: first results of an all year-round monitoring program at $\mathrm{Ny}$-Alesund, Svalbard, Norway. Environ. Sci. Technol. 30, 2294-2304.

Parsons, F., Barrio-Lage, G., 1985. Chlorinated organics in simulated groundwater environments. J. Am. Water Works Assoc., 52-59.

Pavoni, B., Duzzin, B., Donazzolo, R., 1987. Contamination by chlorinated hydrocarbons (DDT, PCBs) in surface sediment and macrobenthos of the river Adige (Italy). Sci. Total Environ. 65, 21-39.

Takeoka, H., Ramesh, A., Iwata, H., Tanabe, S., Subramanian, A.N., Mohan, D., Magendran, A., Tatsukawa, R., 1991. Fate of the insecticide $\mathrm{HCH}$ in the tropical coastal area of South India. Mar. Pollut. Bull. 22, 290-297.

Sarkar, A., Nagarajan, R., Chaphadkar, S., Pal, S., Singbal, S.Y.S., 1997. Contamination of organochlorine pesticides in sediments from the Arabian Sea along the west coast of India. Water Res. 31, 195-200.

Walker, K., Vallero, D.A., Lewis, R.G., 1999. Factors influencing the distribution of lindane and other hexachlorocyclohexanes in the environment. Environ. Sci. Technol. 33, 4373-4378.

Willett, K.L., Ulrich, E.M., Hites, R.A., 1998. Differential toxicity and environmental fats of hexachlorocyclohexane isomers. Environ. Sci. Technol. 32, 2197-2207. 